\title{
A existência fusional e o abuso de crack
}

Guilherme Messas ${ }^{1}$

"Existir é desmentir-se"

Fernando Pessoa

Resumo: Este artigo investiga as condições de possibilidade existenciais de uma população de abusadores de crack no Brasil. O trabalho parte da descrição da essência do ato embriagante para identificar quais as situações antropológicas estruturais de risco para o abuso de crack. Defende que uma forma existencial típica, aqui denominada existência fusional, seja especialmente vulnerável ao efeito agudo e fugaz do crack. Essa vulnerabilidade se dá pela condição préreflexiva de predomínio do presente imediato em relação às outras dimensões da temporalidade. Examinando-se os trajetos pelos quais se desenvolve essa forma de existência, conclui-se que a essência da toxicomania pelo crack é um afunilamento gerado pela condensação de toda a existência em um ponto único de inserção no mundo, com a manutenção rígida de papeis identitários já constituídos e mesmo a exaltação dos perfis anteriores de significação coletiva, o que justifica os frequentes achados psicopatológicos desse grupo.

Palavras-chave: abuso de crack; existência fusional; essência da embriaguez; essência da toxicomania.

\section{The fusional existence and crack cocaine abuse}

\begin{abstract}
This article investigates the existential conditions of possibility of a population of crack cocaine abusers in Brazil. This work initially describes the essence of the drug intoxication; after that, it identifies the anthropological situations at risk of crack abuse. It argues that an anthropological form denominated fusional existence, is specially vulnerable to the acute and transitory effect of the substance. This vulnerability occurs because of the prereflexive dominance of the present in relation to the other dimensions of the temporality. The article examines the ways of development of this existential
\end{abstract}

\footnotetext{
${ }^{1}$ Médico psiquiatra. Mestre em Medicina e Doutor em Psiquiatria pela USP. Membro fundador da Sociedade Brasileira de Psicopatologia Fenômeno-Estrutural. Coordenador da Especialização em Psicopatologia Fenomenológica da Faculdade de Ciências Médicas da Santa Casa de São Paulo. E-mail:messas@fenomenoestrutural.com.br.
} 
form, concluding that the essence of crack dependence is a funneling, motivated by the condensation of the existence into a sole point of insertion in the world. This condition is accompanied by a rigid keeping of stabilized role identities, and even a reinforcement of colective values, that justifies the frequent psychopathogical findings in this group.

Keywords: crack cocaine abuse; fusional existence; essence of intoxication; essence of crack cocaine dependence.

\section{Introdução}

A investigação fenomenológica deve projetar-se em um perímetro de riscos intelectuais, dentro do qual a colheita do saber anuncia-se sempre dúbia, incerta e incompleta. Dentre os enigmas próprios da antropologia, um nos interessará em particular: aquele da ambiguidade imanente da existência, dividida entre permanência e transformação. Somos instigados pelo mistério trivial de, ao longo de nossa biografia, sermos unos e múltiplos ao mesmo tempo. Experimentamo-nos idênticos a nós mesmos à medida que todas as nossas experiências confluem para um irrecusável eu unitário e contínuo, sustentando toda e qualquer vivência. No entanto, provamos simultaneamente nosso deslizamento em relação ao que somos; experimentamos uma evidente fluidez que leva à des-identidade, que faz com que nos saibamos diferentes do que éramos há vinte anos, a ponto de por vezes nem mais conseguirmos nos encontrar em algum ato efetuado em outras épocas da vida. Assim, à positividade da identidade corresponde uma negatividade. Ambas enredam-se em um regime dialético resistente a decifrações simplificadas. Essa impermanente permanência da identidade introduz na antropologia fenomenológica uma tensão na definição de seu campo objetal. A existência ora pode ser investigada em suas essências (Binswanger, 1992), posição que exige um pressuposto ontológico de permanência, ora por meio do exame dos seus sentidos prospectivos, posição que se apoia em uma ontologia (Messas, 2010) e epistemologia (Messas, 2004) da transformação.

A psicopatologia fenomenológica não ficou alheia às dificuldades provenientes da ambiguidade entre conhecimento essencial e dialético 
(Blankenburg, 2012). Com mais força ainda, recebe as tensões dessa dupla perspectiva, à medida que tem de lidar com existências históricas singulares para a compreensão das quais uma reflexão antropofilosófica genérica não é suficiente. A psicopatologia ambiciona o estatuto de ciência humana aplicada e uma ciência não pode se restringir a generalidades: não pode, consequentemente, dedicar-se ao exame de essências abstratas puras, nem tampouco decifrar as existências patológicas sem recurso ao estudo de essências e do movimento biográfico que as dissolve. Assim, um procedimento psicopatológico fenomenológico embrenha-se pelo terreno movediço da investigação da manifestação das essências nas existências (Cutting, 2011), colocando ênfase ora naquelas, ora nestas. É sob essa dissonância epistemológica que procura recuperar a imprecisão ontológica humana que desenvolverei esta contribuição. Escolherei como tema um flagelo sanitário que vem acometendo a sociedade brasileira na última década, o crescimento do número de usuários de crack. Vale acrescentar que, embora se fale de usuários de crack, são em sua larga maioria poliusuários (Bastos \& Bertoni, 2014). Minha intenção com esta reflexão é ampliar a compreensão desse achado epidemiológico, remetendo a categoria descritiva "poliusuário de drogas" às suas bases antropológicas. Com isso, acredito que se possa penetrar intuitivamente nessas experiências pessoais, revelando o sentido tanto do uso contínuo das substâncias - com destaque para o crack - quanto das dificuldades de sua supressão. Parto do pressuposto que a noção de toxicomania, ou de dependência de droga, seja insuficiente. Abrangente demais, essa definição nominal deve ser suplantada por um conhecimento mais próximo das experiências vividas, que pode ser referido a uma forma existencial típica, que denominarei existência fusional. Essa forma existencial que aqui desenvolverei não é a única encontrada na população estudada, mas é aquela que se revelou com maior frequência, possuindo a maior força de tradução do fenômeno antropopsicopatológico e sua dimensão sociopsicológica. O material aqui exposto provém de pesquisa financiada pela SENAD e coordenada pelo sociólogo Jessé Souza, chamada "A gênese social do uso de crack", que 
investigou, por meio de 200 entrevistas abertas, no ano de 2014, usuários de crack nas cidades brasileiras de São Paulo, Porto Alegre, Fortaleza, Salvador e Campos (RJ). Ao longo da exposição, excertos dessas entrevistas serão utilizados para a demonstração de minha posição.

\section{Temporalidade da embriaguez ${ }^{2}$}

Toda toxicomania origina-se de um ato corriqueiro. Igualando a diversidade de efeitos produzidos pelas substâncias, resiste um ponto em comum, a modificação súbita do estado de consciência, voluntariamente procurada. Embora se possa colocar em dúvida esse caráter voluntário em estados avançados de dependência de alguma substância, não restam dúvidas de que tanto no início de quadros clínicos que culminam em alterações psicopatológicas quanto na maioria dos indivíduos, para os quais o uso não rompe os limites da recreação, o ato é guiado pela ação da vontade livre. No entanto, a ação livre da vontade que nos interessa dirige-se pontualmente à mudança brusca do próprio estado de consciência. É a agudeza da embriaguez que a vontade do embriagado objetiva. Não lhe basta alçar-se a outra configuração existencial, é importante que isso se faça de supetão ou ao menos em uma temporalidade mínima que permita que haja um contraste entre o estado imediatamente anterior e aquele produzido pela ação embriagante. Uma embriaguez absoluta, que esfacelasse os vínculos da existência com seu perfil típico consistiria em uma forma de suicídio, de anulação e anestesia distante do que observamos nos desejos triviais daquele que se embriaga. A vontade livre do que se embriaga busca, acima de tudo, um contraste mediado pela temporalidade e fundado na temporalidade. O indivíduo livre procura, por meio do ato de embriaguez, constituir-se como outra temporalidade, permitindo-se sair transitoriamente das imposições da própria história. Essa efêmera libertação das determinações do destino estampa em si mais uma vez a

\footnotetext{
2 Utilizaremos o termo "embriaguez" neste artigo em um sentido amplo, contemplando todas as formas de alteração aguda de consciência promovida voluntariamente por drogas recreativas. Ficam excluídas do conceito as alterações exógenas de origem somática, como doenças metabólicas ou endocrinológicas.
} 
face ambígua de toda a existência, já que a própria saída da história autoriza-se somente pelo contraste em relação àquela. A temporalidade biográfica assim circunscreve-nos por todos os lados: temos de manter uma reserva de identidade para que conjuremos a alteridade em nós mesmos.

Mas examinar a questão do ponto de vista da vontade livre produtora da saída artificial de si mesma não é bastante para aplainar o terreno para nossos propósitos. Se disse acima que a vontade é dita livre para invocar a modificação súbita de suas fundações existenciais, só o fiz por uma licença conceitual, que fez da vontade um artífice mais poderoso do que realmente é e da liberdade individual uma abstração separada ficticiamente do mundo em que está inserida. Na verdade, o poderio da vontade limita-se à convocação da embriaguez. O estado embriagado, por sua vez, é resultado de uma ação essencial exterior à vontade, da qual esta se aproveita. A essência da embriaguez é a redução da temporalidade ao instante, à permanência, ao estreitamento das instâncias trinárias da temporalidade, presente, retenção e protensão, ao seu elemento presente (Messas, 2014). Assim, temos que, agora no nível estrutural, o ato de embriaguez é uma passagem transitória de uma temporalidade aberta, de sustentação trinária a uma temporalidade tendendo à unificação de sua arquitetônica básica.

A essência da embriaguez, entretanto, nada é - salvo uma ideia solta no ar - se não for reconstituída na manifestação de suas raízes situacionais. A saída da temporalidade ditada pela embriaguez desdobra-se em uma infinidade de situações concretas, que não cumpre aqui enumerar. Basta-nos dizer que tanto a celebração inocente entre amigos quanto, por exemplo, o uso de álcool para alívio de alguma angústia, têm como fundamento antropológico a restrição da temporalidade ao instante. Este, tornado hegemônico, pode nos aproximar da comunhão, no primeiro caso, ou nos afastar de nós mesmos, no segundo. Apenas um instante poderoso é capaz de fazer mover as dobradiças do tríptico das linhas de força da temporalidade biográfica. No primeiro caso, por intensificação da importância dos amigos, retirando-os da pluralidade de possibilidades com as quais suas presenças se anunciam a nós (por exemplo, os 
amigos podem ser rivais no papel profissional ou discordantes em posições políticas) e isolando-os em pura fraternidade; no segundo, por atenuação do futuro, a efusão alcoólica nos oferece um momento embevecido e de uma leveza que somente o esquecimento do horizonte temporal da vida permite. Mas até aqui estivemos no campo geral da antropologia, do qual todos fazemos parte sem maiores problemas. Deve-se, agora, examinar a embriaguez como risco.

\section{A embriaguez como risco}

Se a embriaguez é essencialmente permanência, e a existência um pêndulo entre permanência e transformação, a primeira tração que aquela realiza sobre esta é a de conservação. Não se deve entender essa noção de conservação em um sentido valorativo amplo, como uma opção consciente pela não modificação do status quo individual ou social. A conservação aqui remete a um nível mais profundo, de condições de possibilidade da existência, do qual fazem parte, por exemplo, os rituais festivos e as comemorações de datas importantes. Conservar significa também reter aquilo de valoroso que possuímos (como a esperança que reside em nós mesmos) e que tem o poder de embalar a continuidade criativa de nossas vidas e de nos fazer resistir a momentos difíceis. A embriaguez torna-se, contudo, risco quando é recebida por uma existência cuja temporalidade estrutural é vulnerável ao fracasso por meio da dominação do instante sobre as demais dimensões temporais. É em condições extremas antropológicas que mais bem se visualiza essa suscetibilidade. Quando a força exógena da embriaguez, projetando-se sobre a temporalidade da existência, exalta ainda mais uma característica estrutural desta ou, no polo oposto, quando a estrutura da existência necessita medularmente da força conservadora da embriaguez (sem prejuízo de que em algumas biografias haja a síntese das duas condições), temos o caldo de cultura para que o ato trivial de saída da temporalidade histórica se desfigure em toxicomania. Ambas condições prosperam em formas de existência nas quais a dialética da temporalidade humana é gradualmente suprimida pela dominação 
do instante. Por razões de espaço, neste artigo refletiremos apenas sobre a primeira condição. Examinaremos esta forma desde sua condição básica até o desfecho adicto e, uma vez estabelecida essa condição, ponderaremos sobre as dificuldades para sua superação e o papel que a interpessoalidade deve assumir em auxílio a essas existências naufragadas. Essa forma não corresponde especificamente a diagnósticos semiológico-descritivos. Sendo uma forma existencial é transdiagnóstica, colorindo mais de uma categoria de personalidade e fornecendo sentidos diversos para comportamentos toxicômanos assemelhados. Vale lembrar que, no limite, toda existência, justamente por ser temporal, é passível de se tornar adicta a uma substância exógena embriagante. Trata-se de uma condição humana geral que pode ser atingida por vários caminhos diferentes. Por outro lado, e pelo mesmo motivo, não há um destino toxicômano; essa gradual queda da existência sempre pode ser evitada ao longo de seu processo.

\section{O crack como intensa e fugaz paralisação horizontal}

Antes de adentrarmos na forma existencial vulnerável e seus trajetos, devemos nos deter na apresentação das características da essência da embriaguez assumida sob o efeito do crack, que é a cocaína em uma formulação a qual permite a difusão imediata e extremamente aguda de seu efeito. Fumado, permite que seu efeito estimulante atinja o tecido cerebral em segundos, alterando a consciência de modo extremamente veloz. É exatamente essa velocidade extrema que é relatada pelos usuários como motivo principal de uso e razão principal de produção de adicção. O efeito surge e se dissipa rapidamente, exigindo reinstalações contínuas da intoxicação e em intervalos cada vez mais curtos. Ao elemento de velocidade do crack, sua vertente temporal, associa-se seu componente espacial. $\mathrm{O}$ estimulante amplia a horizontalidade existencial, projetando a estrutura da consciência para dentro do mundo interpessoal, social e mesmo material. Todas as experiências relacionadas ao embate direto do indivíduo com o mundo estão exaltadas: 
euforia, irritabilidade, agressividade e até mesmo elevação da capacidade de trabalho são efeitos habituais dessa forma de embriaguez e estão relatadas abundantemente em nossa população investigada. Até mesmo um pensamento mais produtivo pode não deixar de ser uma concessão ao mundo. Ocorre uma simultânea e recíproca elevação valorativa do eu e do mundo. As características dessa exposição excessiva de tudo e todos são de nosso interesse. Menos do que uma independência, pela qual o eu voltaria as costas ao mundo e à alteridade, o crack promove, nas palavras de um dos entrevistados; "...uma sensação de supremacia...de olhar todos com olhar de cima...". O eu afirma-se estritamente pelo contraste com a presença direta, imediata e contínua do outro. A polaridade fundamental da existência, pela qual eu e alteridade aproximam-se e afastam-se em um jogo criativo de influências e concessões é substituída pela condensação interpessoal e pela densidade material. $\mathrm{O}$ polo do eu e o polo do mundo, normalmente em constante apoio recíproco, comprimem-se agora em uma amarra desenredável, constituindo uma posição estrutural de plenitude da qual a euforia é o instrumento sentimental por excelência. O polo do eu já não pode afastar-se do mundo para refletir sobre ele: sua proximidade extrema permite apenas a afirmação e a ação, que testemunhamos nos comportamentos motores hiperativos, na violência ou na expressão mais clara da presença excessiva da alteridade, a experiência persecutória (Di Petta, 2011). A persecutoriedade provocada pelo estimulante mostra a deformação da interpessoalidade em um humano tornado hostil pelo fato de ser ininterrupto e não permitir que dele se abrigue. A embriaguez pelo crack, enfim, aprisiona a temporalidade da existência em um circuito de ênfases interpessoais, que vai cada vez mais se estreitando na medida da frequência do uso. Se, no início, para citarmos uma de nossas entrevistadas, “... a pessoa usa crack porque quer ser forte", essa força volta-se gradualmente contra ela, pois, expondo-a demais à alteridade, acaba por despi-la de modo inclemente diante do social que procurava dominar. Não é casual, portanto, que os usuários de crack se agreguem em comunidades de desvalidos, as ditas cracolândias. A surpresa que setores da imprensa e da opinião leiga revelam ao encontrar nessas 
comunidades estratificações de papeis e uma complexa rede de relações afetivas e hierárquicas nasce do desconhecimento antropológico das suas condições de possibilidade.

Mas com as últimas palavras já ultrapassamos a descrição da essência embriagante do crack e penetramos na progressão que leva à toxicomania. Passemos a investigar a manifestação do efeito essencial conservativo do crack sobre a principal forma existencial vulnerável. E como a existência implica necessariamente movimentos, acompanhemos também a trajetória que culmina na toxicomania.

\section{A existência fusional e seus trajetos}

Se a ação típica do crack é a de instantaneização da temporalidade, pela via da construção de uma espacialidade demasiadamente interhumana, devemos identificar como principal condição de risco a posição existencial na qual é dada pré-reflexivamente uma primazia ao instante mundano, a existência fusional. Essa condição não pode ser catalogada em si como patológica, pois contempla de tendências constitucionais presentes desde sempre na biografia até formações existenciais reativas diante de adversidades intoleráveis. "Não gosto de ficar sempre no mesmo lugar. Sou andarilho, caso, descaso. Fico por aí", relata um entrevistado. Ecoando a história de muitos, atrai nossa atenção para o corriqueiro fenômeno da inquietude, curiosa ou ansiosa, pouco importa aqui, dos usuários de estimulantes em geral. Intranquilidade que leva ao gosto pelo novo, pela aventura, pelo prazer sensorial e ao contato precoce com a embriaguez. Encravados horizontalmente no mundo, saltam de relação a relação, de objeto a objeto, de tema a tema, deixando uma impressão preliminar de serem regidos por radicais ruptura e inconstância (no que se assemelhariam à descrição clássica de Binswanger da fuga de ideias maníaca; 2000). No entanto, não podemos nos deixar enganar pelo exame apenas da expressão vivencial ou comportamental. Examinados na camada fenomênica - no sentido de Minkowski (1995) - de suas vivências,

deixam-nos ver seus saltos laterais, por meio dos quais aparentam somente 
tocar a superfície do mundo e evitar, pela rapidez com que se desfazem daquilo que obtiveram, qualquer profundidade relacional. Entretanto, se perfurarmos com nosso olhar essa camada e atingirmos a ossatura estrutural dessas existências, veremos como de fato estão aprisionados nas relações interpessoais. A sua presumida liberdade é enganosa. De tão aproximados que estão com o mundo, estão aptos a se fundir com ele numa unidade dionisíaca que procura suplantar a temporalidade (Kimura, 2005). Na raiz da inquietude das existências fusionais repousa um anseio pela supressão transversal do tempo. Transversal pois não segue a verticalidade das ambições individuais mas a maciça (con) fusão da coletividade absoluta. A absorção da individualidade na coletividade avança também para o campo dos projetos de vida, fazendo com que a existência fusional adquira seus sentidos desproporcionalmente a partir dos sentidos da coletividade: “Minha recuperação é muito ligada à irmandade que sigo...", expressa um usuário que encontrou um caminho para a saída do crack. Com isso, não queremos dizer que um projeto individual deva se antepor à coletividade ou mesmo que consiga dela prescindir, mas apenas que, na existência fusional, o pêndulo das construções de significado, que oscila entre a ambição singular e a coletiva, pende excessivamente para esta. A exaltação dos valores da coletividade assume, assim, uma coloração extrema nessas existências, de maneira oposta ao que muitas vezes a ingenuidade popular ou midiática anuncia. É moeda corrente nessa população a pungente exclamação: “... tenho vergonha de ir para casa”. A habitual vergonha do usuário é, mesmo se muitas vezes expressa de modo vago, genuína, brotando da sua multiplicada capacidade de coletar a má reputação que tem junto à família e à sociedade. Mas ainda há um agravante para essa exposição gigantesca ao social. Não apenas seus valores são ecos diretos da coletividade como sua expressão é integral, total. Toda experiência consciente surge como iluminação de uma parcialidade da consciência em sua intencionalidade objetal. Assim, por exemplo, mesmo quando gostamos de alguém, somos capazes de identificar pontos dessa pessoa que nos desagradam. A moderação com que a experiência é vivenciada é garantida por nossa capacidade pré-reflexiva de parcializá-la, ou 
seja, de impedir que ela nos assole por completo. A existência fusional, por sua vez, dado seu caráter instantâneo, espacializa suas vivências de modo integral, favorecendo que qualquer sentimento perca sua multiplicidade e ambiguidade. Portanto, não apenas a vergonha pública caracteriza essas estruturas, como uma vergonha total, compacta, refratária a qualquer voz reflexiva interna que possa, relativizando-a, mitigá-la. Decorrem dessa posição as frequentes depressões e desconfortos autorreferentes correntes nos abusadores de crack (Zubarán et al., 2010). A tendência à contenção do fluxo da temporalidade por meio da aglomeração no coletivo já é dada de antemão, pré-reflexivamente, recebendo do efeito euforizante do crack tão somente seu coroamento final, mais acabado e pleno. O estimulante extrai sua capacidade de imantação, portanto, tanto em seus aspectos prazerosos quanto incômodos, de um estilo do existir humano.

Até aqui apenas descrevi uma modalidade humana de estância no mundo no qual o estimulante encaixa-se com facilidade. Nada além de um estilo estrutural da existência em que a euforia, a loquacidade e a agitação são correntes. Percorrer o seu trajeto rumo à transformação toxicômana é fundamental para nosso propósito de revelar como um risco se modifica em deformidade e demonstrar qual é esta em essência. A existência, independentemente de suas tendências, se move e para tal ela necessita de apoio contínuo na interpessoalidade. Temporalizar-se é constituir-se através da alteridade (Lévinas, 2007). É precioso identificarmos como a alteridade se manifesta nessa atmosfera de coletividade absoluta coagida por uma temporalidade instantânea, para que não limitemos nosso entendimento das toxicomanias a uma descrição comportamental ou de suas bases fisiológicas cerebrais. São condições humanas que envolvem a totalidade da existência e só podem ser corretamente entendidas se ampliarmos nosso olhar a esta. A instantaneidade reduz o horizonte sobre o qual se dá a criatividade existencial, restringindo os perfis da identidade do eu e do outro. Como disse acima, o eu culpado e o outro acusador afirmam-se reciprocamente, assumindo uma forma de máxima fixidez. 
No entanto, essa identidade inelástica não significa sua unificação, ou seja, a restrição da identidade a apenas uma atualização de papel, como se vê no desenvolvimento paranoico (este transforma o eu em centro de toda experiência, ao passo que o fusional, como se vê a seguir, tem este centro na multiplicidade que são os outros). Pelo contrário, o estilo de excessiva coesão proporcionado pelo crack acarreta uma forma de pluralidade. Ora, não seria contraditória uma pluralidade assentada no estreitamento da criatividade da identidade? É possível ser plural e rígido ao mesmo tempo? A pluralidade da existência fusional manifesta-se na manutenção rígida e presentificada da diversidade de papeis identitários já constituídos (constituem aqui uma retenção, no entanto, diferente da retenção, por exemplo, melancólica (Tellenbach, 1983; Tatossian \& Moreira, 2012), pois esta não necessita da exaltação compacta do presente. O papel histórico do fusional é mantido pela sua presença exclamativa e contínua: o outro relevante deve estar sempre ali), dos quais os familiares são, necessariamente, os mais importantes pelo fato de serem os mais estáveis. A rigidez da fusionalidade do crack e dos estimulantes manifesta-se pela abolição dos estados intermediários de identidade (a intolerância à ambiguidade, de Kraus, (1990), acorrentando a existência à sua história. O exemplo mais corriqueiro disso - pelo qual seguramente todos os clínicos já passaram - é a recaída no uso de drogas justamente quando um novo movimento vital deve ser exercido. O paciente monta conosco um novo projeto para reconstruir a vida e, com nosso auxílio, chegamos à sua implantação. No entanto, para frustração de todos, nos primeiros passos desse movimento, ocorre do nada uma grande recaída e tudo volta ao que era antes. Também essa frustração, embora justificada, nasce da desatenção para com os fundamentos antropológicos da existência fusional. As transições identitárias são extremamente difíceis para essas estruturas existenciais, pois a temporalidade centrada no presente impede o horizonte de indeterminação necessário para a paulatina transformação rumo à reforma da própria vida. Consequentemente, os papeis já estabelecidos - a muito custo, diga-se de passagem - são de extremo valor para essas existências, conferindo a elas a única estabilidade que 
são capazes de tolerar. Uma vida aprisionada à clareza atormenta-se com o lusco-fusco da abertura biográfica. São extremamente frequentes em nossos entrevistados os relatos de uma queda vertical no crack após a perda de alguma relação significativa ou de algum papel profissional, dado serem estes dois sustentáculos fundamentais para a identidade histórica. A pluralidade da existência fusional é, portanto, uma multiplicidade agregante que, na falta de apoios rígidos na tradição retentiva, lança-se a grandes associações de massa, como torcidas de futebol, seitas, fanatismos políticos ou religiosos (nos quais, inclusive, o elemento embriagante exógeno é facultativo ou mesmo vedado, mais uma vez demonstrando ser essa condição imanente à existência). A força de fixação identitária da massa, mediada pela experiência conjunta de convicção e júbilo, é inigualável.

Cabe, no entanto, fazer a ressalva de que essa fusão pode servir para proteger a existência de condições demasiadamente hostis, justamente por ser capaz de retirá-la da história e oferecer-lhe um presente firme e radioso. Para que a estrutura fusional se transforme em toxicomania é necessário um passo a mais.

\section{A essência da toxicomania pelo crack}

Vejamos a arquitetônica dessa estagnação humana que é a queda no crack. A característica distintiva dela é o afunilamento existencial (o termo "afunilamento" é tomado de um de nossos entrevistados). Com esse termo, quero retratar que a estrutura já desfigurada na toxicomania condensa-se em um ponto único de inserção no mundo (Di Petta, 2014), devido ao efeito da droga, sem, no entanto, perder as bordas de inserção anteriores na interpessoalidade (ao menos até o ponto do estabelecimento de um processo, no sentido de Jaspers (1959), em geral atípico (Souza, 2015). Daí a imagem do funil, objeto aberto à recepção de um grande volume em uma ponta, mas estreito na outra. A toxicomania não esquizofrênica distingue-se, por exemplo, da psicose endógena justamente porque esta perde seus pontos de apoio anteriores na interpessoalidade, procurando um equilíbrio estrutural por meio do delírio 
(Binswanger, 2012). Infelizmente, não poderei me alongar nesse diferencial. Apenas quero retratar com a noção de afunilamento a submissão da existência a um efeito exógeno agudo com preservação - e até mesmo exaltação - do perfil anterior de significação da alteridade. A larga maioria da população entrevistada tem como sonho a retomada ou constituição de uma família e de um papel profissional e, quando envolvida em ato criminal, tem consciência do significado da ação. E, como agente afunilante, o crack tem se mostrado de uma eficácia inaudita: “A maconha e a cocaína ainda foram drogas que eu pude me sociabilizar; o uso de crack foi meu isolamento total". Um isolamento, vale lembrar, assediado por todos os lados. Embora uma leitura tangencial encontre na toxicomania o comportamento exclusivo de uso imoderado da substância (e os comemorativos adjuntos, como a abstinência, que podem requerer atenção médica de emergência), um panorama fenomenológico vê no toxicômano pelo crack a captura simultânea pelo ímã da intoxicação e pelos reclamos do social. Se muitas vezes não divisamos um sentido para a vida do toxicômano, encontramos sempre e fortemente o anseio por um sentido. A toxicomania pelo crack é, em essência, o revés de um sentido, não a ausência dele.

\section{O papel da alteridade na reconstrução da temporalidade histórica}

Todo sentido clama, para sua atualização no solo histórico, por temporalidade. Em consequência, o sentido ao revés do toxicômano enraíza sua titularidade na alteridade. Será ela a responsável pela oferta de temporalidade suficiente para que a estrutura fusional assegure-se da fixação identitária de que não pode prescindir e, ao mesmo tempo, permita o florescer suave de um sentido interior. A radicalidade da importância da interpessoalidade na fusionalidade é, reiteradas vezes, acentuada por nossos entrevistados. Mas tem neste que citamos a seguir seu apogeu: “Queria que um grupo me falasse o que fazer na vida pós-droga. Um drogado nunca faz nada sozinho, sempre pede. E eu tô fazendo. O cara precisa de um direcionamento, senão ele volta".

Dos representantes da alteridade nos cuidados à toxicomania - ou seja, clínicos, acompanhantes, familiares, formadores de opinião - por crack não se 
exige pouco. A sua presença deve ser, por um lado, firme para amarrar a identidade do usuário, invocando uma segurança que pode não ter para si mesmo. Firme para oferecer o horizonte para um projeto existencial que sabe não brotar inicialmente da profundidade do outro. Deve reconhecer a força de influência que sua presença terá sobre o outro, assumindo serenamente para si poderes especiais, conferidos pré-reflexivamente pelo paciente, que tendem a nos produzir também euforia e cobiça. Deve possuir coesão suficiente para manter o sentido oferecido ao paciente sem desviar-se na agressividade e tirania que espreitam em todos os projetos de força (por exemplo, não raramente se vê abusos de poder em instituições de assistência à toxicomania). Ela deve assim restringir sua temporalidade ao instante coeso e pleno de um sentido unitário e definitivo. No entanto, deve ser capaz de dissolver suas convicções próprias para, através da murada da condensação fusional, identificar a germinação de um sentido genuíno para a outra existência. Deve fundir-se ao paciente para posteriormente dela afastar-se. Deve introduzir insidiosamente fraqueza em sua própria força, hesitação em sua própria convicção, renúncia em sua aparente imposição. Deve estar segura de si mesma quando cega pela dúvida. Deve, enfim, assumir para si os cambaleios da existência sustentada por uma temporalidade protentiva, aquela que lança o humano em seus desafios mais profundos. Forte sem deixar de ser elástico, o perfil de identidade daquele que se propõe a auxiliar o toxicômano vai muito além de uma formação técnica apurada ou do treino circunspecto de estratégias de comportamento. Requer um comprometimento existencial integral e complexo, que respeite a sentença involuntariamente prescritiva de um entrevistado: “(...) eu tenho que tá com uma pessoa que é forte emocionalmente". O alvo final desse papel imprescindível da interpessoalidade na toxicomania é enfim restituir a temporalidade da existência, é fazer o humano retomar o frescor da vida: "quando tu se livra da dependência química é como ser criança de novo". 


\section{Referências bibliográficas}

Bastos, F \& Bertoni, N. (2014) Pesquisa Nacional sobre o uso do crack: quem são os usuários de crack e/ou similares do Brasil? Quantos são nas capitais brasileiras?. Editora ICICT/FIOCRUZ.

Binswanger, L. (1992) Drei formen misglückten Daseins. In: Ausgewählte werke. Band 1. Roland Asanger.

Binswanger, L. (2000) Sur la fuite des idées. Éditions Jérôme Millon.

Binswanger, L. (2012) O caso Suzanne Urban. Psicopatologia Fenomenológica Contemporânea. Vol. 1 (1), 198-344.

Blankenburg, W. (2012) Der Verlust der natürlichen Selbstverständlichkeit. Ein Beitrag zur Psychopathologien symptomarmer Schizophrenie. Parodos Verlag.

Cutting, J. (2011) A critique of psychopathology. The Forest Publishing Company.

Di Petta, G. (2011) L'experience paranoide chez les cocaïnomanes. Phénoménologie, psychopatholoige, traitement. in Ballerini A, Di Piazza G (ed): Délirer. Analyse du phénomène delirant. Le cercle herméneutique, vol 17, p. 6578.

Di Petta, G. (2014) Psychopathology of addictions. Psicopatologia Fenomenológica Contemporânea, vol 3 (2), 16-37.

Fiocruz (2014) Pesquisa Nacional sobre o uso de crack. Org. Bastos, F \& Bertoni N.

Jaspers, K. (1959) Allgemeine Psychopathologie. Siebente Auflage. Springer.

Kimura, B. (2005) Scritti di psicopatologia fenomenologica. Giovanni Fioriti.

Kraus, A. (1990) La intolerância a la ambigüedad como variable de personalidade y rasgo estructural de los fenómenos de enfermedad de los maníacos depressivos. An. Psiquiatría, vol 6 (4). P. 153-158.

Levinas, E. (2007) Le temps et l'autre. Presses Universitaires de France.

Messas, G. (2004) Psicopatologia e transformação: um esboço fenômeno-estrutural. Casa do Psicólogo.

Messas, G. (2010) A phenomenological contribution to the approach of biological psychiatry. J Phenomenological Psychol, Vol 41 (2) p. 180-200.

Messas, G. (2014) Psicose e embriaguez. Psicopatologia fenomenológica da temporalidade. Intermeios - Casa de Artes e Livros.

Minkowski, E. (1995) Le Temps Vécu. Presses Universitaires de France, 1995. 
Souza, G. (2015) A fenomenologia dos transtornos psicóticos atípicos: os estados psicoides. In: Psicopatologia da clínica cotidiana. Coopmed. p. 113-125.

Tatossian, A. \& Moreira, V. (2012) Clínica do Lebenswelt. Psicoterapia e psicopatologia fenomenológica. Editora Escuta.

Tellenbach, H. (1983) Melancholie. Problemgeschichte, Endogenität Typologie Pathogenese Klinik. Springer Verlag.

Zubarán C., Foresti K., Thorell M., Franceschini P., Homero W. (2010) Depressive symptons in crack and inhalants users in Southern Brazil. Jethn Subst abuse vol 93. p. 221-36. doi: 10.1080/15332640.2010.501626. 